\title{
Aquaponics - A Process Control Approach
}

\author{
Noel Scattini ${ }^{1} \&$ Stanislaw Paul Maj ${ }^{1}$ \\ ${ }^{1}$ Engineering Institute of Technology, Perth, Western Australia \\ Correspondence: Dr S P Maj, Engineering Institute of Technology, 1031, Wellington St, West Perth, 6005, \\ Western Australia. Tel: 1-300-138-522. E-mail: paulm@eit.edu.au
}

Received: August 9, 2017

doi:10.5539/mas.v11n11p43
Accepted: August 18, $2017 \quad$ Online Published: October 21, 2017

URL: https://doi.org/10.5539/mas.v11n11p43

\begin{abstract}
An aquaponics automation design was undertaken to interpret the system requirements to integrate automation to operate and optimize the system. The system was designed to increase the layers of control over the inputs and outputs to operate the system with a process control approach. The viability of these levels of control over the process was investigated by undertaking a processes design to assess types of instrumentation required and control functions that could be incorporated into the design to optimize the process. The design process incorporated sub-systems that did not rely on a main system, to increase ranges of commercially viable crops. The subsystems do not have the same environmental requirements of the main system and the subsystems environment could be calibrated to meet specific requirements of a selected crop including fruiting vegetable types. The results of the automation design have been tabulated into this article to assess the viability of increased levels of process control to obtain subsystem designs with maximized optimization.
\end{abstract}

Keywords: SCADA, DCS, aquaponics, hydroponic, process control, automation

\section{Introduction}

\subsection{Aquaponics Automation by Decoupling Requirements}

The aquaponics cycle is a biological process between plants, fish and bacteria which must be carefully controlled. The introduction of automation to the aquaponics cycle introduces additional forms of control by manipulating the inputs of the system to aid in controlling the process outputs. To understand the level of equipment that must be introduced into the process and the level of software development that would be required, an analysis was conducted in order to define the requirements of an aquaponics system that had full automation similar to a process controlled plant. Process control can be used to both control a process and reduce inefficiencies with constant monitoring and reduce (Evans, 2016) process variability. Process Control automation is able to apply repeatable results as ranges or parameters of the process can be programmed or measured, which can be controlled for (Bozich, 2010) predictable results. Aquaponics have existing known parameters that optimize (Richard V. Tyson, 2011) results for fish and bacteria, yet plants that produce fruiting vegetables also have known optimum conditions that include lower $\mathrm{pH}$ for nutrient uptake and nutrient levels. According to Scattini (Noel Scattini in press, 2017) "The use of process control and the automation that it incorporates is able to measure and maintain multiple control loops, having multiple control loops that are not dependent on others would remove some of the identified limitations by dividing the process to meet those ranges that have been researched as optimum at particular stages of the process."

\subsection{Aquaponics Subsystems}

The wastewater treatment component of the process allows biological bacteria processes to take place, which change waste ammonia to nitrites and nitrates. The fish effluent requires $\mathrm{pH}$ 's of 7.2 to 7.8 (FAO, n.d.) for the bacteria to transform the ammonia nitrates. Once changed to nitrates the nitrogen is in a form (Sawyer, 2013), which can be taken up by plants as a food source in turn cleaning the water for re-use by the fish.

The wastewater treatment also allows solids to be removed or reintroduced back into the system as dissolved solids (Hijran Yavuzcan Yildiz, 2017) that supply plants additional nutrients. The fish species to be grown have limitations on the amount of (Zealand, 2000)Total Dissolved Solids and other water quality requirements that must be met if the produce is to be resold. The dissolved solids are able to be removed to a storage tank in a concentrated form, which allows for decoupling of the $\mathrm{pH}$ 's between the fish effluent and the effluent concentrate to optimize both the main systems and the subsystems requirements. The nutrient concentrate is to 
be reintroduced into a hydroponic sub-system to reduce fertilizer requirements that would be required to produce the chosen crop. The hydroponic system ranges are controlled by instrumentation measurement and the delta in nutrients are met by adjustment to meet desired nutrient ranges depending on the crop of vegetables to be grown. Supplying the optimum requirements into multiple subsystems and separating control loops between fish, bacteria and plants could be achieved with increased levels of process control automation. To determine the amount of effort to implement this level of control on an aquaponics process a preliminary design was required. This design determined the complexity of measurement and types of automation control that would be required to keep parameters ranges under control. Achieving these levels of control could assist commercial aquaponics operators to benefit by being able to produce an increased range of produce that does not rely on a single control loop or a single control loop that needs to compromise to sustain all requirements. Process control that increases the level of control over secondary loops could maximize the recycling of nutrients from waste, lower fertilizer costs and increase the viability of a technology that reduces water usage within its system.

\subsection{Viability of Process Control Automation in Aquaponics}

To gain an understanding of what is required to automate components of the process, a design of a system was undertaken in order to identify additional equipment required to add control functions to the process with additional levels of control with automation. Automation to operate a process can include many types of equipment from hardware that could include flow switches, instrumentation, and various types of control valves, analyzers and Variable Speed Drives. To operate the process within desired ranges software functions are provided from a distributed control system or SCADA to control the system within desired parameters. The instrumentation hardware and SCADA software can be broken down into further sections either passive devices or active devices. Passive devices are those that provide a readout or indication (ANSI, 2009) which could be represented as a local gauge or a software representation on the Human Machine Interface. Other passive devices could include monitoring functions that can be used to determine ranges that are outside of the optimized range. Active devices are those that operate a function or an auxiliary device (ANSI, 2009); these auxiliary functions could be from hardware such as control valves, relays and solenoids. The output normally initiates a variable that modulates the device or process to a predetermined set point, which in this design would be a range that has been documented as optimum for the particular control loop.

\subsection{Process Control Equipment used for Optimization}

Flow switches are commonly used in process control to identify that flow is taking place within piping which in an aquaponics system would identify if there were pipe blockages in the system. Flow switches are used to monitor flow detection in tank drains and can be a reliable method (Craig, n.d.) of protecting equipment. In the design being assessed in this paper, the flow switches have been used to identify multiple flows from a tank that could have failures from pumps or from a blocked pipe. The identification of such a failure could prevent a tank from draining or overflowing or the tank not receiving enough cycled water that could cause a fish kill in the system. Flow control valves are used to control the flow by restriction yet can often be interpreted as wasteful (Tahara, 2016) as they oppose the flow by restricting it. The flow valves in the design of the process have been utilized in circumstances where head pressure from a tank can supply energy required for flow. Additionally flow restrictive valves have been selected where flow restriction could aid the plant by circulating more of the opposing flow to prevent anaerobic pockets building up when upstream flow is not required in the process. Variable Speed Drives are used in conjunction with pumps by adjusting the speed to control flow (Muhammad $\mathrm{H}$ Al-Khalifah, 2012), to aid in the control process streams. Variable speed drives not only supply a greater level of control to flow but also minimizes the energy costs as pumping systems can account for $20 \%$ energy usage (Technologies, n.d.)in process facilities (depending on final configuration or if the plant has heating, pumping costs could be a considerable higher percentage). In an aquaponics wastewater system, clarifiers can be used to settle out the solids produced by fish waste. The clarifiers allow solids to be removed for either total removal or in this design to a mineralization tank (Lennard, 2012) for further biological treatment. Having flow control over the solids from the clarifiers has the benefit of limiting the total amount of effluent being removed from the main process stream for further treatment as additional energy would be required to treat or pump the additional effluent. Instrumentation is introduced as passive devices to measure the process constantly. The instrumentation used to aid in process control includes $\mathrm{pH}$ and nitrate analyzers to relay measurements, which are displayed on the Human Machine Interface. The monitoring also includes more complex analyzers that are able to carry out multiple measurements to monitor the minerals or nutrients that are available in the process. 


\section{Method}

\subsection{Defining Items Required for Process Control}

Established design tools such as (ISA, 2014) a Process Flow Diagram (PFD) and Piping and Instrumentation Diagram (P\&ID) were employed in order to design the process control system. Established ranges were used to ensure optimization in different control loops and existing methods to maintain these ranges. The control loops for the subsystems and its associated requirements for optimization are met by adapting existing technologies to provide conditions, which have the ability to provide known documented outcomes. The use of established design techniques such as Failure Mode and Effect Analysis (Noel Scattini in press, Aquaponics Automation Design Techniques, 2017) "has highlighted that there are many instrumentation and controls that could mitigate or prevent some of the technical failures that have occurred in aquaponics processes in the past." The combination of existing research and results from design tools and procedures were used to determine the number and type of instruments, which could be used to automate features of the process. The number of instruments and types of alarms and alarm tags where listed onto an instrumentation and alarm list to identify the level of automation that would be required to control the process.

\subsection{Plant Configuration}

To compare the design and number of devices that can be put into perspective with similar designs such as those that contain batch processing a design configuration was selected that contained multiple tanks. The aquaponics process consists of eight fish rearing tanks and a wastewater treatment plant that treats the effluent from the fish tanks. The biological wastewater treatment component of the plant also included a degassing tower that can accommodate an additional fan to force air through the degassing tower. The fan however is not expected to be required in the plants day to day operations (designed with but not fitted), this type of fan is required in plants that have high stock densities. The fan however could be fitted in plants that risk high density farming practices or plants that require additional cooling during summer as it has a (James M. Ebeling, 2006) cooling effect on the water. The instrumentation list does not include the stand-alone instruments on the skid-mounted equipment for the adapted filters. The filters do however allow for start stop functions, along with fault functions to interface with the SCADA/DCS system. The design was established with known existing ranges that have been documented from past research as being optimized for different components of the plant, either ideal bacterial $\mathrm{pH}$ 's ranges of nutrients that are required for the plants to produce fruiting vegetables. These have been separated into subsystem control loops to reach optimized production rates to the established known ranges. To separate these alternate control loops, technologies from alternate industries have been adapted to obtain these established ranges.

\section{Results}

\subsection{Results of Integrating Process Control Functions}

The data represents an overview of different components of the process and what is required to automate sections of the process. This data represents items that would be required to establish cost data, to conduct a cost analysis of integrating the equipment into a process plant. The data could be used to establish data for integrating equipment into an existing plant and a comparison of cost savings could be analyzed against additional viable commercial crops or the risk mitigations that benefit the plant operator. This data could also be used to establish design data for a new plant, which would be expected to be easier to integrate as the system could be designed with the plant features initially in the design. The results are divided into two sections one that has an overview of the hardware components and two a section that has an overview of software components. The two sections list the relevant results, which elaborate on some of the uses of hardware and software, additionally the level of complexity required to automate the plant with process control functions is explained in greater detail.

\subsection{Software Data Analysis}

The results are tabulated from the instrumentation and alarm list that was incorporated onto a piping and instrumentation diagram that represents the process. The results of software requirements equipment selection to be incorporated into the design was selected and the quantities quantified in Table 1 to represent the overall requirements of this process layout. The alarms and associated levels of priority are also listed in Table 1 . The alarms also have event alarms which may note when a pump is started or stopped for later reference which could be used to determine operating or failure times of pumps to introduce maintenance measures in the future operations to increase the reliability of the process plant. 
Table 1. Software Functions

\begin{tabular}{cc}
\hline Software Alarms/Tags & Number \\
\hline Tags / Human Machine Interface & 241 \\
Alarms / Event Only & 61 \\
Alarms / Low Priority & 41 \\
Alarms / High Priority & 24 \\
\hline
\end{tabular}

Table 1 shows the number of Human Machine Interface Software tags required for functionality of the Human Machine Interface. These include tags from instrument measurements or from digitised push buttons that can function from a mouse or touchscreen from the Human Machine Interface, some of which include start or stop functions for plant equipment. Other software components of the design included tags from analogue signals that operate displays on the Human Machine Interface to display ranges of measured devices. The alarms could be driven from analogue or digital devices from measurement being out of range from an analogue signal. Digital signals to operate alarms could be from an initiation of an emergency stop in the field or from a relatively basic instrument such as a float level switch. The software besides including analogue and digital interfaces to operate displays can also include more complex software features. The hydroponics pump has requirements to operate for a period on then another period off, to flush unused nutrients from the root zone, and rehydrate the zone for a set period. This operation required a start tag on the Human Machine Interface that initiated timers to carry out this function; this is also commonly referred to as a software sequencer or PLC sequencer. Additional functions using inputs from flow switches and the start functions of pumps have been utilised to initiate flow alarms to individual tanks and alarm a main audible and visual alarm, these individual tank alarms are able to identify and localise the fault.

\subsection{Hardware Data Analysis}

The plant also requires hardware devices either to control measured values for them to remain in optimum known ranges or to obtain those measured values. The results of the design have been accumulated into Table 2 for discussion.

Table 2. Hardware Devices

\begin{tabular}{cc}
\hline Devices & Number \\
\hline Compressors & 2 \\
Variable Speed Drives & 5 \\
Fans & 3 \\
Adapted Filter Units & 2 \\
Valves & 32 \\
Instruments (includes multiple output Analysers) & 73 \\
Pumps & 15 \\
\hline
\end{tabular}

The devices in Table 2 represent totals of hardware devices to operate the process with a DCS/SCADA system. The devices included instruments that include basic operations that communicate with digital signals and measurement analyser to supply values such as $\mathrm{pH}$ ranges. More complicated instruments such as nutrient analysers could be described as small field laboratories that contain multiple outputs to send analogue outputs to the SCADA/DCS system to represent ranges of measured nutrient values. The variable speed drives are utilised in the plant to carry out speed control with indication displayed on the SCADA/DCS Human Machine Interface with speed control also displayed. The variable speed drives are able to control the motor speed that in turn controls the flow, in areas of the process to optimise the process or alternately only use energy required to carry out function to save on energy costs.

\section{Discussion}

The completion of an automation design allows the requirements of a process plant to be understood before implementing a project. The results allow for cost savings in fertilsers in comparison to size of known process plants to be calculated and the value of return understood on capital investments required to implement this technology. Although process plants could vary in size with items such as the number of fish rearing tanks, a complete instrumentation list has been developed and the list could be adjusted to meet the requirements of individual process plants. This type of overall installation of this industrial automation equipment is aimed at 
supplying large commercial operations that have large overheads such as high fertilizer or pumping costs, or alternately need to compete with diverse crop ranges. An additional function that the instrumentation and control provides besides the measurement of ranges and controlling these subsystem loops for separation for optimized results. The additional functions also allow for implementation of risk mitigations to prevent failures in the plant and increase reliability. The results showed that there was a large number of software tags required to automate the plant, with built in process control functions. The instruments selected to integrate process control functions into the plant ranged from relatively inexpensive instruments such as flow switches. Yet there was also more complex instrumentation required to measure minerals or nutrients to monitor the ranges for correct dosing. These are more expensive yet can monitor multiple nutrient levels and can carry out functions that are similar to a lab, and display results in real time. Although expensive, the constant monitoring of these nutrients supplies constant levels that could be calibrated to specific plants requirements. Other factors besides cost savings of fertilizers should also be considered as the DCS/SCADA system combined with the constant monitoring would mitigate the risk of fish kills or other unexpected events, which potentially cost operators in lost stock and the amount of fish feed they had invested in them.

\section{References}

ANSI. (2009, September). ANSI/ISA-5.1-2009 Instrumentation Symbols and Identification . Retrieved from https://edisciplinas.usp.br/pluginfile.php/1881581/mod_resource/content/0/ISA\%205-1\%202009.pdf

Bozich, D. (2010). The Process Control Imperative. Retrieved from http://www.productionmachining.com/articles/the-process-control-imperative(2)

Craig, S. (n.d.). Flow Switches For Refinery Water/Wastewater Control. Retrieved from http://www.fluidcomponents.com/assets/media/Articles/Refinery-Water-WWT-0513.pdf

Evans, K. (2016, Oct 7). Advantages of Process Control. Retrieved from http://www.engineeringresourcecenter.com/blog/advantages-of-process-control

FAO. (n.d.). Bacteria in Aquaponics. Retrieved from http://www.fao.org/3/a-i4021e/i4021e05.pdf

Hijran Yavuzcan Yildiz, L. R. (2017). Fish Welfare in Aquaponic Systems: Its Relation to Water Quality with an Emphasis on Feed and Faeces—A Review. https://doi.org/10.3390/w9010013

ISA. (2014). Control and Field Instrumentation Documentation. Retrieved from https://www.isa.org/pdfs/news/chapter7-control-loop/

James M. Ebeling, P. (2006). Biofiltration Biofiltration-Nitrification Nitrification. Retrieved from https://cals.arizona.edu/azaqua/ista/ISTA7/RecircWorkshop/Workshop\%20PP\%20\%20\&\%20Misc\%20Pape rs\%20Adobe\%202006/7\%20Biofiltration/Nitrification-Biofiltration/Biofiltration-Nitrification\%20Design\% 200verview.pdf

Lennard, P. W. (2012). Aquaponics System Design Parameters: Solids Filtration, Treatment and Re-use. Retrieved from https://www.aquaponic.com.au/Solids\%20filtration.pdf

Muhammad H Al-Khalifah, G. K. (2012). Control valve versus variable speed drive for flow control. Retrieved from http://automation.isa.org/wp-content/uploads/2012/06/Control-Valve-vs-Variable-Speed-Drive1.pdf

Noel Scattini in press, S. P. (2017). Aquaponic integration and automation - a critical evaluation. Modern Applied Science.

Noel Scattini in press, S. P. (2017). Aquaponics Automation - Design Techniques. Modern Applied Science, In Print.

Richard V. Tyson, D. D. (2011, February). Opportunities and Challenges to Sustainability in Aquaponic Systems. Retrieved from http://horttech.ashspublications.org/content/21/1/6.full

Sawyer, J. (2013). Aquaponics-Growing-Fish-and-Plants-Together. Retrieved from http://fisheries.tamu.edu/files/2013/10/Aquaponics-Growing-Fish-and-Plants-Together.pdf

Tahara, C. (2016, June). VFDS: AN ALTERNATIVE TO VALVES FOR MECHANICAL THROTTLING. Retrieved from https://www.flowcontrolnetwork.com/vfds-an-alternative-to-valves-for-mechanical-throttling/

Technologies, U. D. (n.d.). Variable Speed Pumping - A Guide to Successful Applications. Retrieved from https://www1.eere.energy.gov/manufacturing/tech_assistance/pdfs/variable_speed_pumping.pdf

Zealand, A. A. (2000). Australian and New Zealand Guidelines for Fresh and Marine Water Quality. Retrieved from 
https://www.environment.gov.au/system/files/resources/e080174c-b267-455e-a8db-d3f79e3b2142/files/nwq ms-guidelines-4-vol3.pdf

\section{Copyrights}

Copyright for this article is retained by the author(s), with first publication rights granted to the journal.

This is an open-access article distributed under the terms and conditions of the Creative Commons Attribution license (http://creativecommons.org/licenses/by/4.0/). 